\title{
APLICAÇÃO DE FERRAMENTAS DE GESTÃo VISANDO A REDUÇ̃̃O DE PERDAS NO PROCESSO DE PRODUÇÃO EM UMA FÁBRICA DE VIDROS CAPIXABA
}

\section{APPLICATION OF MANAGEMENT TOOLS AIMING TO REDUCE LOSSES IN THE PRODUCTION PROCESS IN A CAPIXABA GLASS FACTORY}

\author{
Flavio Lucio Santos de Carvalho ${ }^{1^{*}} \&$ Tiago de Nardi Mattos ${ }^{2}$ \\ 12 Centro Universitário Salesiano - Unisales. \\ 1* fcarvalho@salesiano.br ${ }^{2}$ revistabjpe@ gmail.com
}

\section{ARTIGO INFO.}

\section{Recebido em: 21.10.2021}

Aprovado em: 02.02.2022

Disponibilizado em: 08.02.2022

\section{Palavras-chave:}

Vidros planos; mesa de corte; chapas de vidro; PDCA; Ishikawa; perdas; processo; lead times; SWOT,

\section{KEYWORDS:}

Plan glasses; cutting table; plates glass; PDCA; Ishikawa; losses; process; lead times; SWOT.

*Autor Correspondente: Carvalho, F. L. S., de.

\section{RESUMO}

O cenário atual exige das empresas a otimização dos processos, seja na utilização de ferramentas, aproveitamento de matéria-prima, ou até mesmo a locação dos colaboradores, proporcionando a produção enxuta. Assim é de grande importância a atenção aos processos, para reduzir não somente os lead times mas também as perdas durante a fabricação dos produtos. Baseado no ideal de reduzir desperdícios, o presente estudo tem como objetivo identificar o setor onde ocorrem as maiores perdas e agir para minimizar ou eliminar estes indicadores de perdas no processo produtivo avaliado. Para atingir os resultados através da pesquisa, foram coletados vários dados do processo de produção da fábrica, como as perdas mensais, a quantidade produzida mensalmente e o rendimento dos colaboradores durante a execução das atividades. Realizando a aplicação das ferramentas
Diagrama de Pareto, Matriz SWOT, Diagrama de Ishikawa, 5W's 2H's, e ciclo PDCA foi possível identificar o ponto crítico do processo e quantificar as perdas norteando a tomada de decisão. Assim foi desenvolvido um plano de ação para atuar no setor de corte de vidros, setor inicial e de maior volume de entrada e saída de pedidos da organização durante o processo produtivo.

\begin{abstract}
The current scenario requires companies to optimize processes, whether in the use of tools, use of raw materials, or even the hiring of employees, providing lean production. Thus, attention to processes is of great importance, to reduce not only lead times but also losses during product manufacturing. Based on the ideal of reducing waste, this study aims to identify the sector where the greatest losses occur and act to minimize or eliminate these loss indicators in the evaluated production process. In order to reach the results through the research, several data from the factory's production process were collected, such as monthly losses, the monthly quantity produced and the employees' income during the execution of activities. By applying the Pareto Diagram, SWOT Matrix, Ishikawa Diagram, 5W's 2H's, and PDCA cycle tools, it was possible to identify the critical point of the process and quantify the losses guiding decisionmaking. Thus, an action plan was developed to work in the glass cutting sector, the initial sector with the largest input and output volume of orders in the organization during the production process.
\end{abstract}



processo de produção em uma fábrica de vidros capixaba. Brazilian Journal of Production Engineering, 8(2), 99-115.

\section{INTRODUÇÃO}

Em um mercado cada vez mais competitivo, exige-se das empresas, uma otimização de seus processos, assertividade na utilização de ferramentas, aproveitamento máximo de matériasprimas, eficiência na locação dos colaboradores, proporcionando assim uma produção enxuta. Assim é de grande importância a atenção aos processos, para reduzir não somente os lead times mas também as perdas durante a fabricação dos produtos. Baseando-se nestes quesitos, foi realizado um diagnóstico organizacional que serviu para identificar de forma mais precisa a empresa Estrela Vidros (objeto de estudo), suas áreas produtivas e demais atividades.

Visualizando os processos produtivos, estudou-se a produção do vidro plano, descreveu-se que a linha produtiva é composta pelos setores de corte, lapidação, furação, lavadora, forno de têmpera, embalagem e expedição. Após uma realização diagnóstica, foi identificado que no setor de corte de vidros é onde ocorreu a maior demanda de produtividade da empresa, devido ao fato de ser a atividade inicial, e aplicada a todos os produtos produzidos, ou seja, todo vidro produzido deve ser cortado inicialmente, mas nem todo vidro produzido deve-se seguir os processos produtivos subsequentes, pois existem necessidades diferentes para cada aplicação solicitada pelos clientes (beneficiamentos ou aprimoramento de propriedades mecânicas). Consequentemente o setor em questão, possui os maiores índices de perdas durante o processo de fabricação do produto.

Em seguida realizou-se um estudo de caso, no qual, através da leitura e análise das teorias e procedimentos de gestão de processos, foi possível criar decisões estratégicas, possibilitando melhorias para os problemas detectados, ou seja direcionar com precisão as possíveis mudanças a serem feitas, para que futuramente, possam diminuir o custo de produção reduzindo a quantidade de perdas, e elevando o lucro final.

Então, constatou-se que a empresa objeto de estudo, apresenta um elevado índice de perdas de matéria-prima durante o processo produtivo, e que através de uma análise realizada no período de outubro de 2020 até maio de 2021, voltando as atenções da organização aos seus processos internos, identificando o que poderia ser feito para a reduzir ou eliminar o problema de perdas no processo produtivo?

Deixando de forma clara o problema, iniciou-se uma análise nos procedimentos, visando identificar gargalos durante a execução das atividades, buscando soluções para as não conformidades. Caso não houvesse a tratativa para a situação identificada, poderia se tornar um agravante, implicando no possível aumento do número de perdas, devido à ausência do planejamento e controle da produção.

Portanto o foco da pesquisa é identificar em qual etapa do processo ocorrem as maiores perdas e atuar nesse processo, apresentando resultados através da redução do número de perdas recorrentes da fabricação dos produtos da empresa Estrela Vidros. E forma mais específica realizar aplicação de ferramentas de gestão de processos, visando o melhor aproveitamento dos operadores na execução das atividades, reduzindo os custos otimizando o aproveitamento durante o uso de matéria-prima, identificando os gargalos ou processos onde ocorrem as maiores perdas e criando planos de ação para reduzir o número de perdas. 

processo de produção em uma fábrica de vidros capixaba. Brazilian Journal of Production Engineering, 8(2), 99-115.

\section{REFERENCIAL TEÓRICO}

Para a realização do diagnóstico organizacional, foi desenvolvida uma análise dos processos, embasada nas teorias de grandes nomes do cenário de gestão da produção.

A revisão bibliográfica foi direcionada às metodologias de identificação de falhas durante a execução das atividades, que forneceu suporte para a elaboração de sugestões corretivas perante as não conformidades constatadas.

\subsection{Diagrama de Pareto}

Através do estudo da ferramenta de gestão denominada diagrama de Pareto, foi possível identificar os pontos fracos do processo produtivo e aplicar os esforços com maior assertividade. A aplicação dessa ferramenta é realizada através de uma relação de 20/80 (lê-se "vinte para oitenta") onde seria possível solucionar $80 \%$ dos problemas aplicando somente $20 \%$ dos esforços. Segundo Seleme e Stadler (2012), “Juran estabeleceu uma classificação dos problemas de qualidade, dividindo-os em poucos vitais e muitos triviais, ou seja, a maior quantidade dos defeitos se refere a poucas causas."

\subsection{Matriz Swot}

Segundo Shahir et al. (2008), o termo SWOT tem origem no inglês e é uma sigla de Forças (SStrengths) e Fraquezas (W-Weaknesses), Ameaças (T-Threats) e Oportunidades (OOpportunities), também conhecida como F.O.F.A. a qual é representada pelas palavras na língua portuguesa, embora reordenadas diferentemente. Identificando o problema, deve-se estudar as possíveis causas e oportunidades no âmbito interno da organização como um todo, para essa identificação, foi aplicado a ferramenta Matriz SWOT ou Análise SWOT. Essa ferramenta possibilita identificar os pontos fortes e fracos do ambiente interno de um determinado segmento, demonstrando riscos e oportunidades que possam estar envolvidas no âmbito externo. De acordo com Chiavenato e Sapiro (2015), sua função é cruzar as oportunidades e as ameaças externas à organização com seus pontos fortes e fracos.

\subsection{Diagrama de Ishikawa}

Com o problema principal do negócio e suas forças identificadas, foi possível entender as próprias limitações, e obter informações para desenvolver a próxima ação, realizando um estudo minucioso a fim de descobrir o motivo que está ocasionando grandes perdas, e tomar decisões assertivas. De acordo com Ishikawa (1993) o agrupamento dos fatores deve ser corretamente controlado a fim de que os processos sejam transformados em causas que resulte em bons produtos e efeitos. Para isso, foi realizada a aplicação da ferramenta denominada diagrama de Ishikawa, comumente chamado de diagrama espinha de peixe. A visão para identificar os problemas é criada a partir das opiniões de quem vive na área, e através de um brainstorming junto aos envolvidos no processo, é possível identificar os motivos das dificuldades de operação, para posterior atuação baseada nos mesmos. "Os funcionários da organização são envolvidos para discutir problemas e propor soluções de melhoria da qualidade" (Peinaldo \& Reis, 2007). 

processo de produção em uma fábrica de vidros capixaba. Brazilian Journal of Production Engineering, 8(2), 99-115.

\subsection{Ciclo PDCA}

Para EWALD e SILVA (2020) O termo lean production é definido como uma metodologia que gera bons resultados com qualidade e redução de custos que são características que identificam os sistemas de produção eficientes, eficazes e ágeis. O método científico do ciclo PDCA ( $P$ : Plan; D: Do; C: Check; A: Act) ou (Planejar; Fazer; Checar ou Verificar; Aplicar, Agir ou Padronizar) desenvolvido por Shewhart e Deming (1939) é constituído em três etapas, especificação, produção e inspeção correspondem, respectivamente, a fazer uma hipótese, realizar um experimento e testar a hipótese. Essas três etapas constituem o processo científico dinâmico de aquisição de conhecimento.

Para a efetivar a produção enxuta baseada nos problemas apontados, será aplicada a ferramenta denominada ciclo PDCA, essa ferramenta nada mais é do que um plano de ação para tratativa de problemas, executada de forma cíclica e com foco na qualidade. $\mathrm{O}$ ciclo atua por meio das etapas de planejamento, desenvolvimento, controle e ajuste, sempre retornando ao início do processo, buscando a melhoria continua. "Deming buscou sintetizar sua experiência no Japão, como preleção para a mudança organizacional necessária, com ênfase na liderança e na participação de todos na organização" (Carvalho \& Paladini, 2019).

\subsection{Ferramenta 5W's 2H's}

A ferramenta $5 \mathrm{~W} 2 \mathrm{H}$ foi introduzida por profissionais do ramo automobilístico do Japão com intuito de auxiliar a utilização da ferramenta de qualidade PDCA, principalmente em seu planejamento (Silva, 2013). A aplicação desta ferramenta é realizada de modo a questionar os envolvidos no processo com perguntas instigadoras durante um brainstorming, sendo elas "Quando?" (When?) “O que?” (What?) "Por que?" (Whay?) "Onde?” (Where?) "Por quem?" (Who?) "Como?” (How?) "Quanto?” (How Much?), onde suas respostas acabam esclarecendo os problemas, ou organizando as ideias para a resolução dos problemas. Seu propósito na pesquisa será efetuado de modo a tratar perdas exponenciais com ações corretivas, de curto a médio prazo, visando o controle estatístico da pesquisa, para a entrega de dados coniventes.

\section{METODOLOGIA}

O presente trabalho se mostra como uma pesquisa exploratória, descritiva e aplicada, buscar uma familiaridade maior com o cenário que a empresa apresenta e com os conhecimentos científicos, no qual foi exposto no problema com o objetivo de propor uma melhoria no processo produtivo quanto suas perdas.

A pesquisa realizada de forma quantitativa/qualitativa, buscando contabilizar e identificar a quantidade de problemas apresentados, a mesma apresentará o cunho qualitativo, aplicando ferramentas no intuito de obter qualidade no processo produtivo.

Os métodos assim aplicados foram para a realização da pesquisa foram estudos bibliográficos, obtendo conhecimentos e referencial teórico para a realização do estudo de caso.

Para o procedimento de levantamento e análise de dados, foram feitas entrevistas com os envolvidos no processo de produção, onde os resultados foram apresentados durante a criação do diagrama de Pareto, e estudos estatísticos emitidos pelo software de gestão da empresa objeto de estudo cujo nome é Estrela Vidros, situada no endereço: Rua Monteiro Lobato ${ }^{\circ}$ 84, Bairro: Serra do Anil, Cariacica - Espirito Santo. 

processo de produção em uma fábrica de vidros capixaba. Brazilian Journal of Production Engineering, 8(2), 99-115.

O processo de levantamento de dados e análise da pesquisa em questão se deu no período de outubro de 2020 até maio de 2021, visando identificação do problema de perdas no processo produtivo estudado, envolvendo equipes de colaboradores de cada etapa produtiva. Abaixo temse um diagrama esquemático do procedimento metodológico deste trabalho.

Figura 1. Diagrama do processo metodológico utilizado na pesquisa.

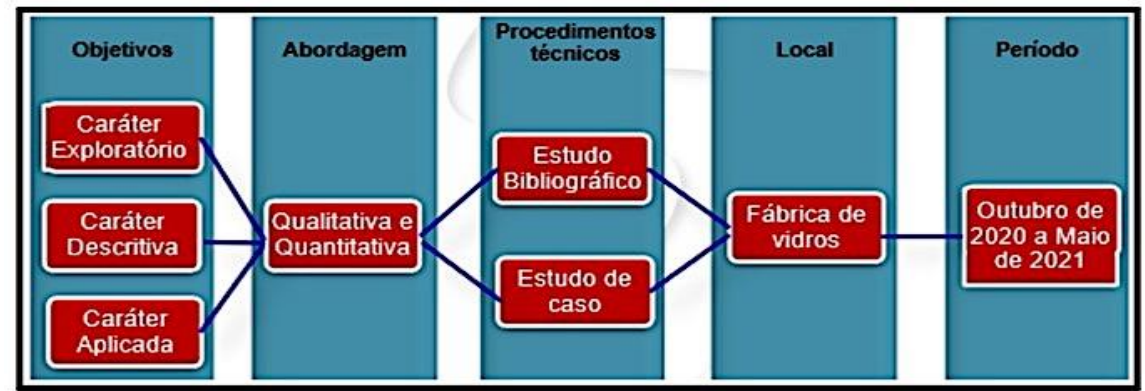

Fonte: Autores (2021).

A pesquisa tem, portanto como objetivo, apresentar resultados pertinentes as falhas na produção, e formas de reduzir o índice de perdas no processo, evidenciando dados estatísticos que possam nortear decisões e investimentos que alcancem melhorias contínuas. Oliveira (2013), estipula que a atividade de controlar deve ser entendida como o processo de coletar e retroalimentar informações sobre o desempenho, de maneira que os responsáveis pelas tomadas de decisões possam comparar os resultados realizados com os resultados planejados e decidir como proceder a respeito de distorções ou problemas diagnosticados.

\section{RESULTADOS E DISCUSSÃO}

\subsection{Descrição do Processo Produtivo}

O processo para a fabricação interna do produto é iniciado no setor comercial, quando o cliente realiza o pedido customizado, informando a espessura, cor, medidas e acabamentos que serão realizados no vidro. Em seguida é foi realizada a digitação do pedido no sistema integrado de gestão da empresa, que por sua vez será exibido para o setor de Planejamento e Controle da Produção (PCP), que irá realizar a programação de produção baseada nas menores datas de entrega, e priorizando o envio de pedidos com serviços mais longos, garantindo a produtividade e entrega final conforme os prazos estabelecidos.

Os processos de otimização dos pedidos são feitos baseados nas dimensões das chapas de vidro presentes no estoque de matéria-prima, com medidas que variam desde 3,21 metros de comprimento por 2,20 metros de altura, até 6,0 metros de comprimento por 3,21 metros de altura.

Após a otimização dos pedidos na chapa, o PCP encaminha o plano de corte juntamente com as etiquetas de cada pedido para a mesa de corte automática realizar o corte das peças na chapa, assim que a mesa termina o corte superficial, os operadores do setor de corte devem realizar a colagem das etiquetas em cada peça, baseada no plano de corte previamente estabelecido pelo setor de PCP, em seguida realizam o destaque das peças, e alocando-as em carrinhos para que sejam transportadas para os setores seguintes.

O setor seguinte é o de lapidação, que realiza o acabamento dos cantos do vidro, a fim de remover as extremidades cortantes, é realizada a rotação das peças nas máquinas de lapidação

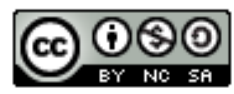



processo de produção em uma fábrica de vidros capixaba. Brazilian Journal of Production Engineering, 8(2), 99-115.

linear, cada peça realizará 4 movimentos até que todos os lados do vidro sejam lapidados. Sequencialmente as peças que terão furos ou recortes seguem para o setor de marcação, coletando o código de barras na etiqueta da peça, será feita a análise do projeto do cliente e serão marcados todos os furos ou recortes que o pedido venha possuir utilizando caneta corretivo nos gabaritos de ferragens, sinalizando a medida dos furos, recortes ou acabamentos.

Em sequência, com base nas medidas e áreas demarcadas pelo setor anterior, são realizados os furos ou recortes no setor de furação, utilizando furadeiras manuais com diferentes espessuras de brocas e escariadores. O próximo setor é a lavadora que realiza a lavagem das peças, a fim de remover os resíduos remanescentes dos processos anteriores. Para vidros comuns, as peças se dirigem para o setor de embalagem e em seguida seguem para a expedição realizar a entrega para o cliente. Em casos de vidros temperados, as peças são enviadas para o setor de conferência identificar se há alguma não conformidade que possa comprometer o vidro durante o tratamento térmico de têmpera.

$\mathrm{O}$ último processo produtivo é o forno de têmpera, o qual fornece o aquecimento das peças a temperatura de aproximadamente $600{ }^{\circ} \mathrm{C}$, realizando assim o tratamento térmico do material produzindo então o vidro temperado, vale ressaltar que este processo pode ser realizado ou não, visto que este é específico em função da demanda do produto final. Em seguida as peças são levadas para o setor de expedição, que por sua vez realiza a separação das peças em cavaletes com suas respectivas rotas, é realizada a programação de entrega das peças focando nas datas de entrega de cada pedido, e finalmente é carregado o caminhão com a carga pertinente a sua rota, em seguida se dirige a seus respectivos clientes, grande parte das vezes vidraçarias. Segundo Oliveira (2013) deve-se assegurar reconhecimento e atendimento contínuo e rápido aos diferentes tipos e classes de clientes (Figura 2).

Figura 2. Fluxograma de processos para a fabricação de vidros planos.

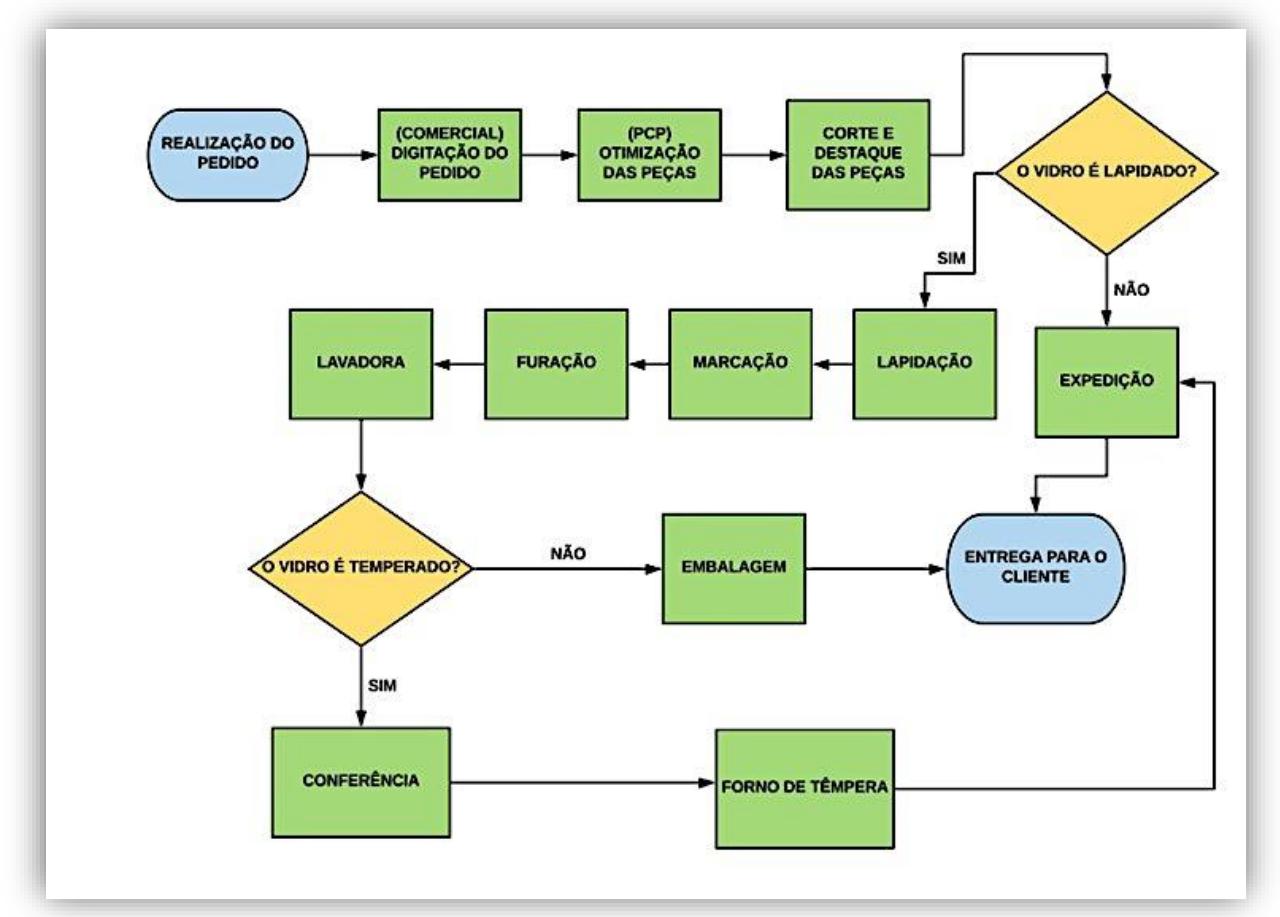

Fonte: Autores (2021).

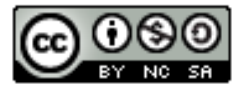



processo de produção em uma fábrica de vidros capixaba. Brazilian Journal of Production Engineering, 8(2), 99-115.

\subsection{Identificação do Problema}

O Passo inicial do processo de melhoria ocorreu durante a análise de relatórios emitidos pelo Sistema Integrado de Gestão (SIG) da empresa, que constatou altos indicadores de perdas, sendo relatadas por quebras de manuseio do produto, ou avarias que comprometam a qualidade do mesmo, danificando-os. Durante a análise iniciada no período de outubro de 2020, a empresa apresentava um cenário de $\mathrm{R} \$ 26.000,00$ em perdas internas do produto pronto, englobando qualidade, quebras e descartes, este número representava 2,29\% do faturamento mensal da organização, um número elevado para representar o âmbito produtivo interno. $\mathrm{O}$ alto índice de perdas chamou atenção ao setor de PCP, que por sua vez identificou a capacidade de melhorias por meio do controle de produção, utilizando ferramentas de gestão, sendo estas descritas a seguir.

\subsection{Aplicação do Diagrama de Pareto}

Houve o levantamento dos dados por meio de relatórios emitidos pelo SIG de forma mais sucinta, identificando cada setor e sua respectiva quantidade produzida diária, tal como sua quantidade perdida. Ao reunir os dados, aplicou-se a ferramenta diagrama de Pareto, buscando identificar o setor que havia o maior índice de perdas e atuar neste de forma de fossem gerados resultados mais assertivos.

Para a realização e aplicação da ferramenta houve a análise produtiva trimestral dos setores de corte, furação, forno, lavadora, conferência e embalagem, que por sua vez apresentaram dados coletados através de relatórios emitidos pelo software de gestão, que computa todas as informações de cada peça em cada setor, a partir do momento em que os vidros são coletados na entrada dos setores.

Para a criação do diagrama de Pareto, os dados foram calculados com base na identificação do percentual de perdas, baseado na relação de quantidade de metros quadrados produzidos por metros quadrados perdidos durante o processo, que possibilitaram a aplicação do 20/80.

Conforme o Gráfico 1 abaixo foi realizada a análise trimestral de perdas no processo em todos os setores da produção de outubro a dezembro de 2020.

Gráfico 1. Resultado trimestral de perdas nos setores da organização no ano de 2020.

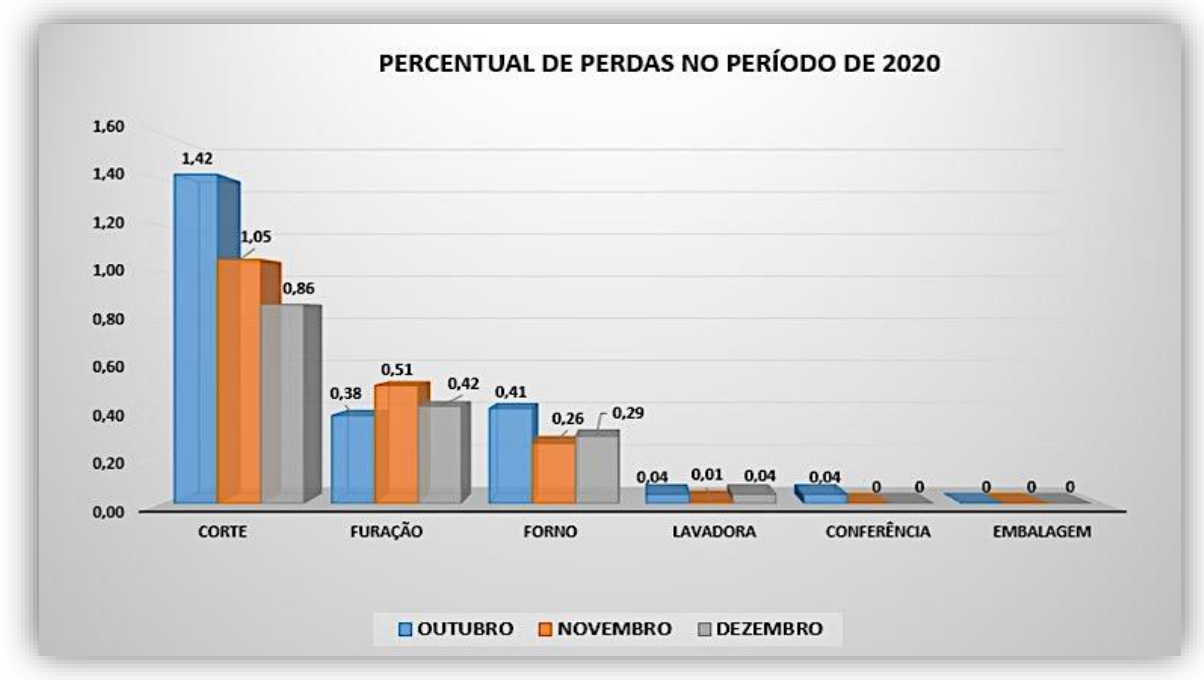

Fonte: Autores (2021). 

processo de produção em uma fábrica de vidros capixaba. Brazilian Journal of Production Engineering, 8(2), 99-115.

A análise trimestral representada pelo gráfico acima informou que o ponto de maior ocorrência é o setor do corte, com a parcela equivalente a $67 \%$ das perdas totais da área produtiva da empresa.

Baseado na metodologia de Pareto, foi possível então a identificação do principal motivo das perdas no processo produtivo, e focar os esforços em solucionar o maior dos problemas, obtendo maiores resultados. Identificando a área de maior ocorrência de perdas da produção foi possível prosseguir com o estudo, aplicando a ferramenta denominada matriz SWOT para identificar os riscos e oportunidades que serão enfrentadas no processo de melhoria do setor do corte.

\subsection{Análise SWOT}

Chiavenato e Sapiro (2015) definem a metodologia de análise de ambiente SWOT como sendo cruzar as oportunidades e as ameaças externas a uma organização com seus pontos fortes e fracos. Seguindo a ideia de identificar o ponto crucial das perdas, e com o estudo da bibliografia, foi possível desenvolver a análise SWOT do setor de corte da empresa, sendo exemplificados os riscos e oportunidades a serem alcançados, tal como suas fraquezas e forças no âmbito produtivo. O quadro a seguir remete a análise SWOT do setor de maiores perdas no processo.

Quadro 1. Aplicação da análise SWOT no setor de corte.

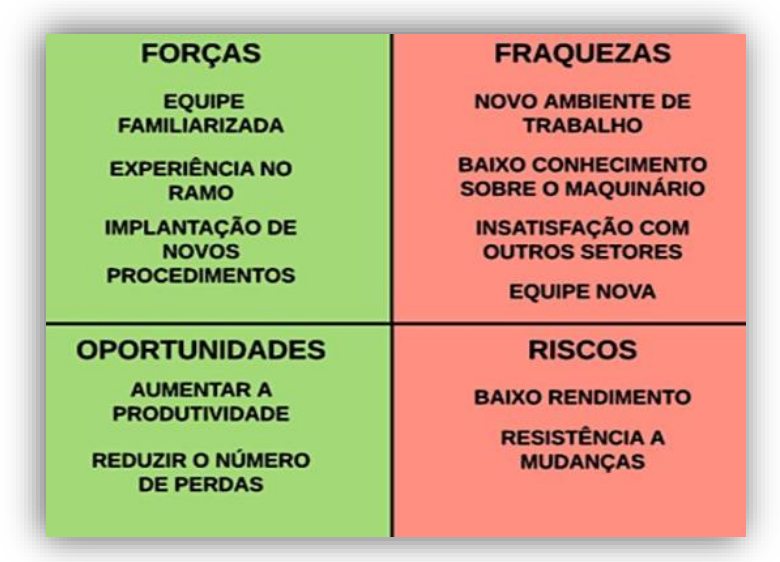

Fonte: Autores (2021).

\subsubsection{Forças e Fraquezas}

Foi possível identificar as forças e fraquezas que o setor de corte apresenta através de registros dos funcionários, análise setorial, e entrevista com os colaboradores. Os pontos fortes identificados foram:

- Os colaboradores possuem experiência na área e trabalharam em outra empresa do mesmo segmento, apresentando familiaridade e afinidade, proporcionando fácil convivência e possibilidade de rotatividade entre outros setores.

As fraquezas encontradas no setor foram:

- Baixo conhecimento ao operar uma máquina automática programada encontrada em um novo ambiente de trabalho, devido ao fato de a equipe ter sido contratada a apenas 3 meses, apresentando insatisfação com os serviços de outros setores durante a adaptação a nova empresa.

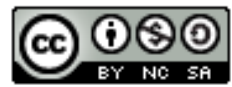



processo de produção em uma fábrica de vidros capixaba. Brazilian Journal of Production Engineering, 8(2), 99-115.

\subsubsection{Riscos e Oportunidades}

As oportunidades de crescimento e desenvolvimento identificadas no setor de corte foram cruciais para nortear as melhorias a serem adotadas, focando em reduzir o número de perdas, e aumentar a produtividade do setor. $\mathrm{O}$ risco que a equipe possa vir a apresentar seria a relutância a mudanças de procedimentos, devido a experiência e familiaridade dos colaboradores, implicando em outro risco identificado, que é o baixo rendimento.

A análise SWOT proporcionou uma visão sistêmica do processo de corte de vidros, norteando os esforços em melhorias e análises mais aprofundadas e estruturadas pertinentes ao setor analisado.

\subsection{Aplicação do Diagrama de Ishikawa}

Foi realizada uma reunião com os colaboradores do setor do corte, a fim de descobrir as dificuldades que os operadores apresentam durante sua jornada de trabalho, tal como os motivos dos elevados índices de perdas apresentados. Para Tubino (2017) o Total Quality Control (TQC) define um processo como a reunião organizada de seis fatores, ou causas, conhecidos como os (“6M`s”) (Matérias-Primas, Máquinas, Mão de Obra, Métodos, Medidas e Meio Ambiente). Conforme mostra a Figura 2, foi possível identificar os principais motivos das perdas junto a equipe do setor de corte.

Figura 2. Aplicação do Diagrama de Ishikawa no setor de corte.

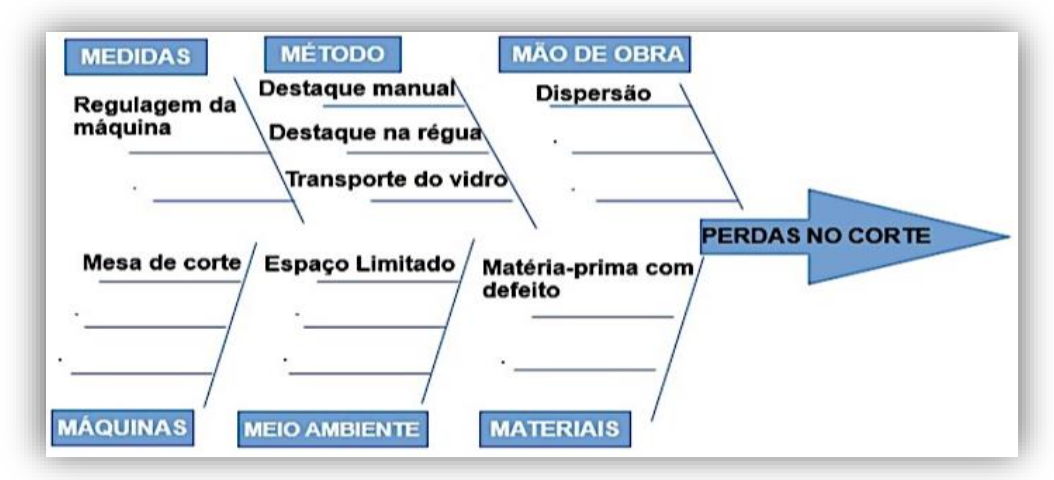

Fonte: Autores (2021).

\subsubsection{Causas e efeitos identificados}

Após a reunião com os colaboradores durante um brainstorming a respeito dos motivos das perdas, foi identificado que um dos fatores causadores das perdas se enquadrava na categoria de medidas, os colaboradores perceberam dificuldades ao destacar os vidros, e ao conferir os procedimentos, estava sendo utilizada a pressurização de corte da máquina inferior ao esperado pela espessura de vidro a ser cortado.

Outro motivo aparente e de grande relevância estava envolvendo o método de trabalho, inicialmente os colaboradores destacavam as peças irregularmente, utilizando as mãos para separar os vidros, ao invés de utilizar as ferramentas adequadas, como por exemplo o alicate de destaque. $\mathrm{O}$ destaque dos vidros utilizando a régua pneumática da mesa estava sendo feito de maneira indevida, aplicando de maneira desordenada, acarretando em quebra de chapas ao meio.

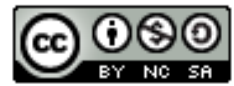



processo de produção em uma fábrica de vidros capixaba. Brazilian Journal of Production Engineering, 8(2), 99-115.

O método de transporte também estava sendo feito irregularmente, carregando múltiplas peças pequenas de uma vez só, gerando atrito entre as peças e ocasionando perdas por arranhões.

Outra causa identificada pelo diagrama de causa e efeito foi a mão de obra dispersa, a falta de cobrança e liderança deixou a equipe desatenta e desnorteada, acarretando em perdas por falta de atenção, tal como troca de etiquetas, avarias durante o transporte, dentre outros. Mais ativos causadores dos problemas foram visualizados no processo, tais como o maquinário, que por sua vez foi identificado a necessidade de manutenções, a mesa de corte apresentava desnivelamento, fazendo com que as peças deslizassem, o carpete estava bem desgastado, implicando na preservação do produto durante a operação.

O meio ambiente também apresentou riscos de quebras, enquanto os colaboradores executam a atividade de movimentar os vidros da mesa de corte para os carrinhos de transporte, apresentando um espaço limitado com capacidade para ser otimizado.

O último fator identificado foi a matéria-prima, o material utilizado é o de maior volume produtivo, tal como apresentou o maior índice de quebras, o mesmo foi identificado pelo fornecedor, apresentando uma mistura diferente, deixando o vidro mais rígido ao destacar, acarretando em quebras com maior incidência. Com base nos problemas identificados foi criado um plano de ação baseado na metodologia de melhoria contínua, o ciclo PDCA.

\subsection{Aplicação do Ciclo PDCA}

O ponto crucial para o desenvolvimento do plano de ação teve início logo após a identificação dos motivos das quebras no processo, utilizando o diagrama de causa e efeito foi possível quantificar as perdas e agir de forma assertiva nas tomadas de decisões. A aplicação do PDCA iniciou-se com a primeira etapa do ciclo, o planejamento. Foi criado um plano de ação para tratar as principais causas identificadas no diagrama de Ishikawa. O PDCA representa o ciclo eficiente na resolução de problemas, ou seja, realizar melhorias por etapas e repetir o ciclo de melhoria várias vezes (SHIBA, 1997).

\subsubsection{Plano de Ação (Plan)}

Inicialmente foram abertas ordens de serviço para que o mecânico realize manutenções que possam agregar valor à execução do processo de corte e destaque de vidros. As ordens de serviço abertas foram para melhorar o ambiente e metodologia de trabalho, as melhorias destacadas foram:

- O nivelamento da mesa de corte

- A troca do carpete da mesa de corte

- Implantar refletores para auxiliar na visibilidade com vidros incolores

- Executar treinamentos sobre os procedimentos e metodologias para o destaque de vidros

- Troca das luvas utilizadas pelos colaboradores, melhorando a pegada das peças enquanto transportam o vidro da mesa para o carrinho de transporte.

\subsubsection{Aplicação das melhorias (Do)}

Conforme foi descrito no plano de ação, as melhorias começaram a ser implantadas no período de janeiro de 2021, focando na otimização e especialização da equipe, a fim de reduzir a maior 
Citação (APA): Carvalho, F. L. S., de. \& Mattos, T. de N. (2022). Aplicação de ferramentas de gestão visando a redução de perdas no processo de produção em uma fábrica de vidros capixaba. Brazilian Journal of Production Engineering, 8(2), 99-115.

quantidade de motivos das perdas, os métodos. O operador do computador da mesa foi treinado e familiarizado com o maquinário, aumentando sua capacidade de análise para alterar manualmente os planos de corte enviados pelo setor de PCP, para aproveitar peças que possam estar nas bordas de chapas defeituosas, evitando perdas desnecessárias. As chapas podem ser avariadas no transporte, na movimentação utilizando a ponte rolante, ou até mesmo defeito na composição durante a fabricação. Conforme a Figura 3 a seguir pode-se observar que a perda poderia ser evitada caso houvesse a troca da peça 5 pela peça 8 .

Figura 3. Manipulação manual do plano de corte buscando salvar peças nas bordas.

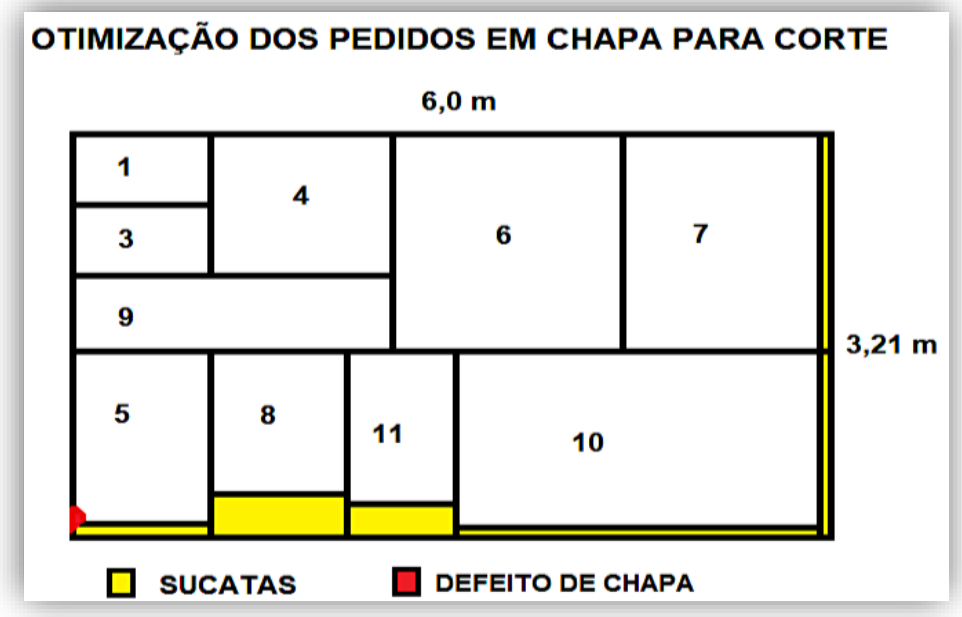

Fonte: Autores (2021).

Seguindo as instruções fornecidas durante o treinamento, os colaboradores passaram a evitar perdas somente realocando as peças de acordo com os problemas encontrados na chapa, sejam eles arranhões, quebras ou bolhas no vidro.

Foram instalados os refletores no local, melhorando a visibilidade do setor, possibilitando maior facilidade para enxergar tais defeitos. Houve também a troca do carpete da mesa, o mesmo já estava gasto e poderia ocasionar arranhões, ou até mesmo queda das peças da mesa devido ao desnível.

\subsubsection{Verificação dos resultados (Check)}

Assim que as melhorias começaram a ser implantadas, foi criado um plano para acompanhamento baseado na relação de peças produzidas por peças perdidas, visando uma meta de $0,5 \%$ de perda, estipulada baseando-se na média dos outros setores. O setor apresentava em média $1 \%$ de perda mensal, um valor alto se comparado com a produtividade e preço dos produtos, o objetivo é reduzir esse valor pela metade e seguir agindo com ações futuras para minimizar ao máximo o número de perdas.

Com isso, iniciou-se a análise mensal utilizando os novos procedimentos e melhorias implantadas no mês de janeiro de 2021, que seguiu sendo acompanhado diariamente. O mês de janeiro apresentou bons resultados como mostra o Gráfico 2, alcançando a média mensal de $0,52 \%$ de perda. 
Citação (APA): Carvalho, F. L. S., de. \& Mattos, T. de N. (2022). Aplicação de ferramentas de gestão visando a redução de perdas no processo de produção em uma fábrica de vidros capixaba. Brazilian Journal of Production Engineering, 8(2), 99-115.

Gráfico 2. Percentual de perdas em janeiro.

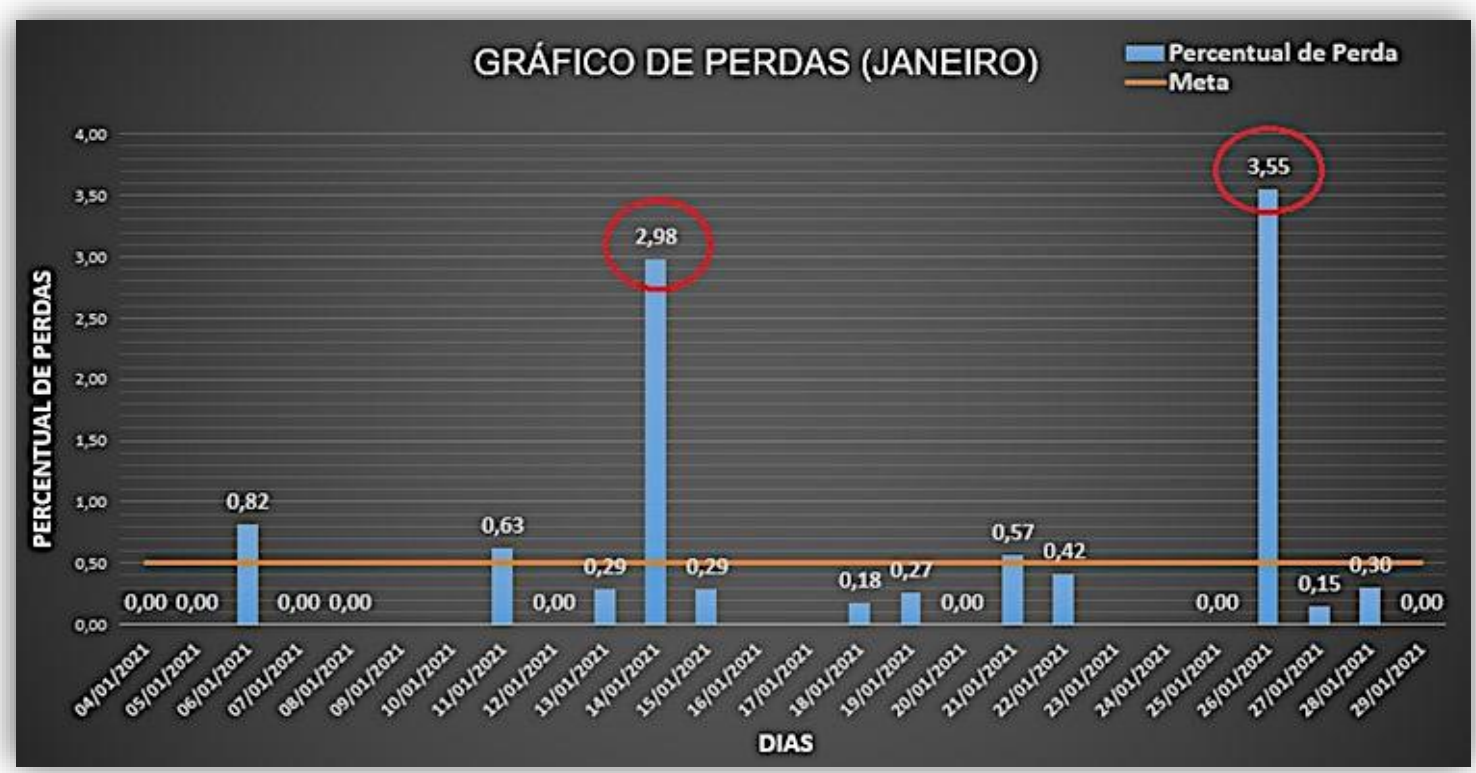

Fonte: Autores (2021).

Conforme o gráfico percebe-se que em janeiro obteve-se um bom resultado, porém dois pontos fora da curva fizeram com que o setor não alcançasse a meta no mês vigente, eles foram identificados e tratados de acordo com a metodologia dos $5 \mathrm{~W}$ 's e $2 \mathrm{H}$ 's verificando que as elevações nas perdas ocorreram devido a falha operacional ao realizar o destaque de vidros com espessuras menores, resultando em quebras. A padronização dos métodos nesse mês ajudou no processo de melhoria contínua para os próximos meses.

O segundo mês após o início das atividades de melhorias apresentou resultados positivos, embora a adaptação ainda não tenha sido concluída, são notórios os resultados. Conforme a análise do Gráfico 3, fevereiro foi o primeiro mês a bater a meta, alcançando 0,44\% de perda.

Gráfico 3. Análise das perdas diárias no mês de fevereiro.

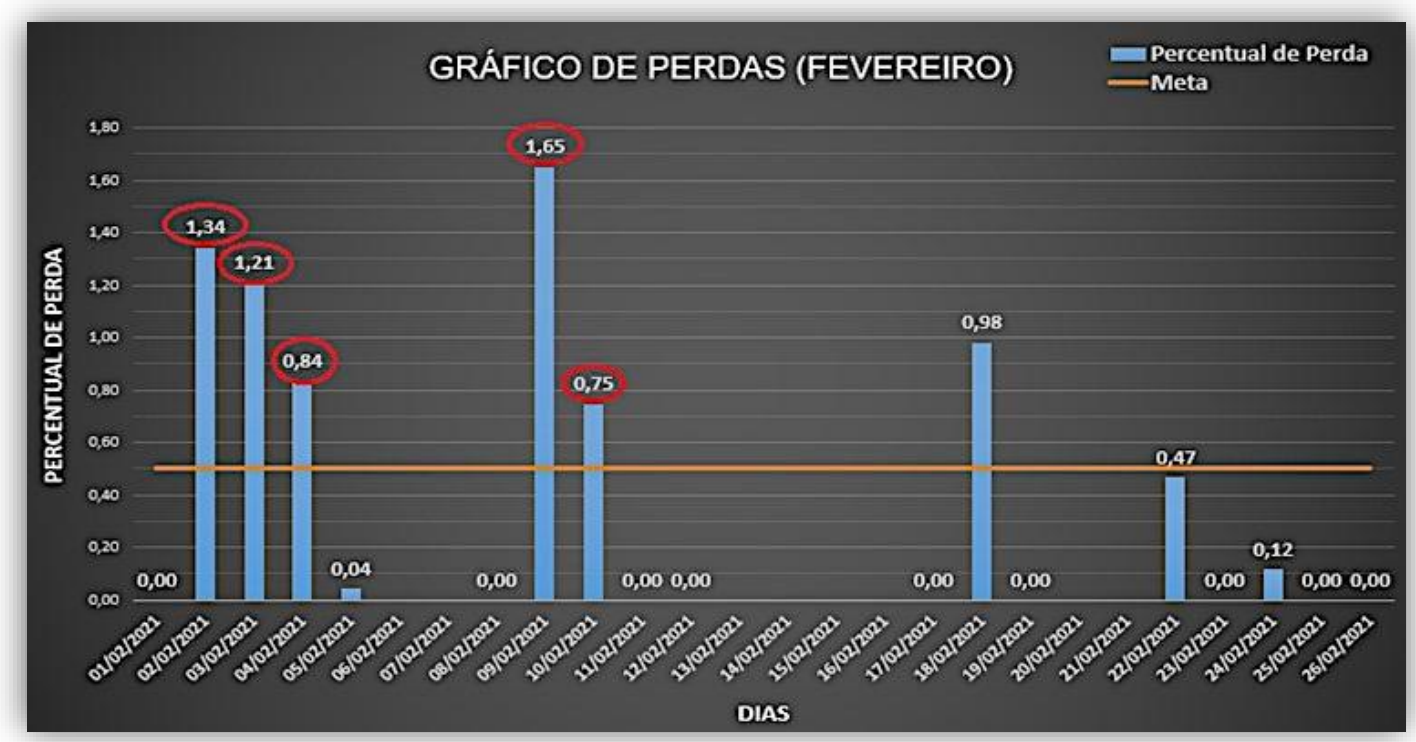

Fonte: Autores (2021).

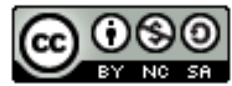

Esta obra está licenciada com uma Licença Creative Commons Atribuição-Não Comercial-Compartilha Igual 4.0 Internacional. Brazilian Journal of Production Engineering, São Mateus, Editora UFES/CEUNES/DETEC. 

processo de produção em uma fábrica de vidros capixaba. Brazilian Journal of Production Engineering, 8(2), 99-115.

Ao analisar o período do mês de fevereiro, percebe-se muitos pontos acima da meta, porém os que estão abaixo da meta tendem a zero. Ao identificar a crescente no início do mês utilizou-se novamente a ferramenta do 5W's $2 \mathrm{H}$ 's para encontrar a causa, e foi constatado que o destaque estava sendo mais difícil e gerando muitas quebras, ao pesquisar a fundo identificou-se que havia vazamento de pressão para o diamante pneumático de corte do equipamento, realizando a manutenção no dia 11 foi perceptível o desempenho do setor em condições normais de trabalho.

No terceiro mês ocorreu aumento no preço do vidro, gerando uma alta demanda por parte dos clientes, que anteciparam os pedidos para pagar mais barato pelos produtos. No decorrer do mês de março o equipamento apresentou desgaste, gerando desnivelamento da régua pneumática de destaque e da própria mesa de corte, mesmo com as adversidades o percentual de perdas continuou a cair, alcançando a meta novamente atingindo $0,38 \%$ de perda (Gráfico 4).

Gráfico 4. Percentual de perdas referente ao mês de março.

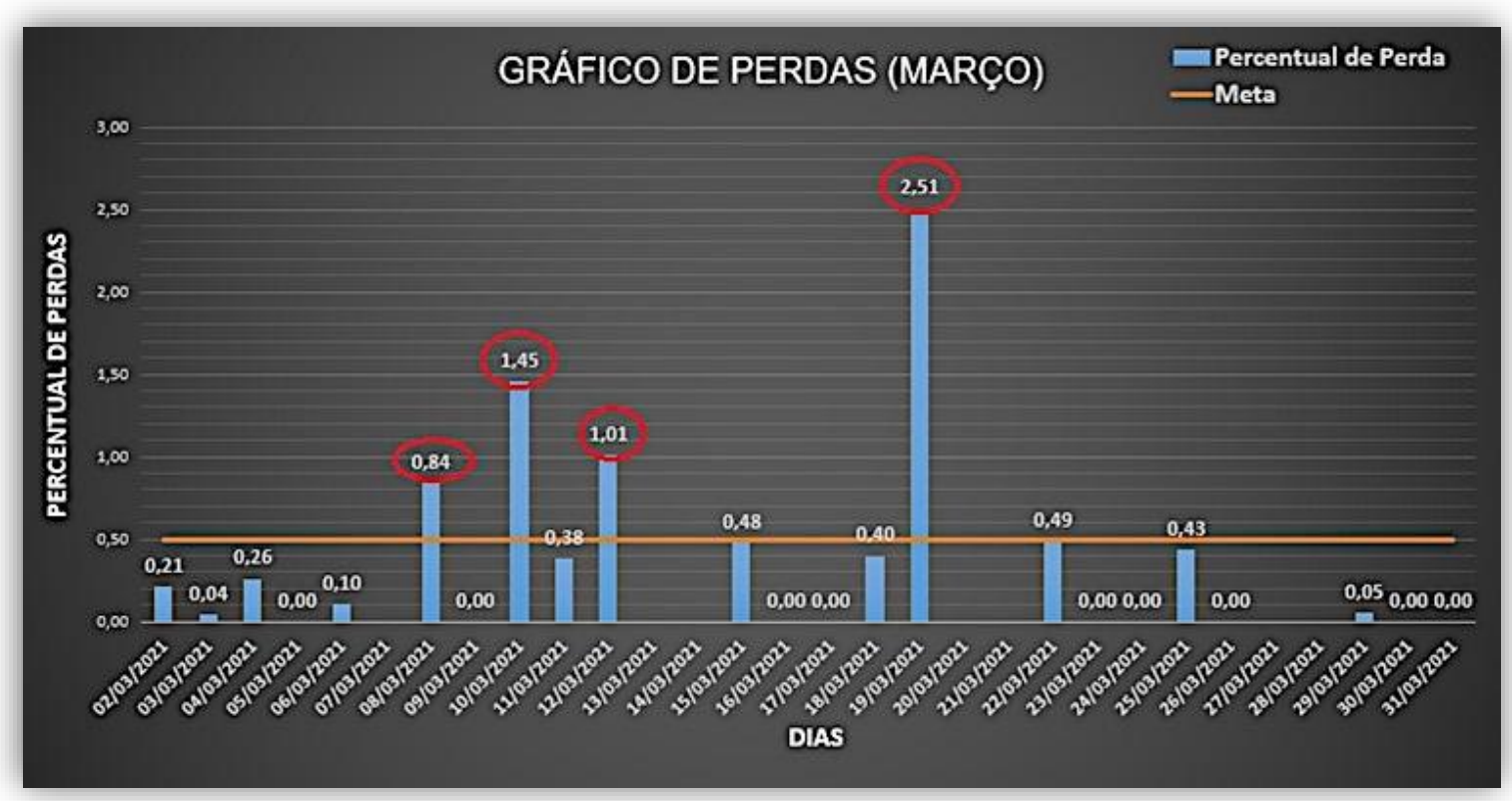

Fonte: Autores (2021).

No período do mês de abril foi identificado apenas dois grandes picos acima da meta, ocasionados por falha operacional ao executar uma montagem de espelhos, esse pedido consiste em diversas peças que devem ser cortadas lado a lado em uma única chapa, qualquer troca de peça influencia milimetricamente a montagem fazendo com que a mesma seja perdida por completo.

$\mathrm{O}$ operador inverteu o desenho da montagem na máquina de corte, causando diferença de medida entre as peças, porém ao analisar o Gráfico 5 nota-se que o setor continuou na tendência de baixa, resultando em $0,37 \%$ de perda mensal.

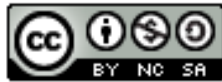


Citação (APA): Carvalho, F. L. S., de. \& Mattos, T. de N. (2022). Aplicação de ferramentas de gestão visando a redução de perdas no processo de produção em uma fábrica de vidros capixaba. Brazilian Journal of Production Engineering, 8(2), 99-115.

Gráfico 5. Percentual de perdas diárias no mês de abril.

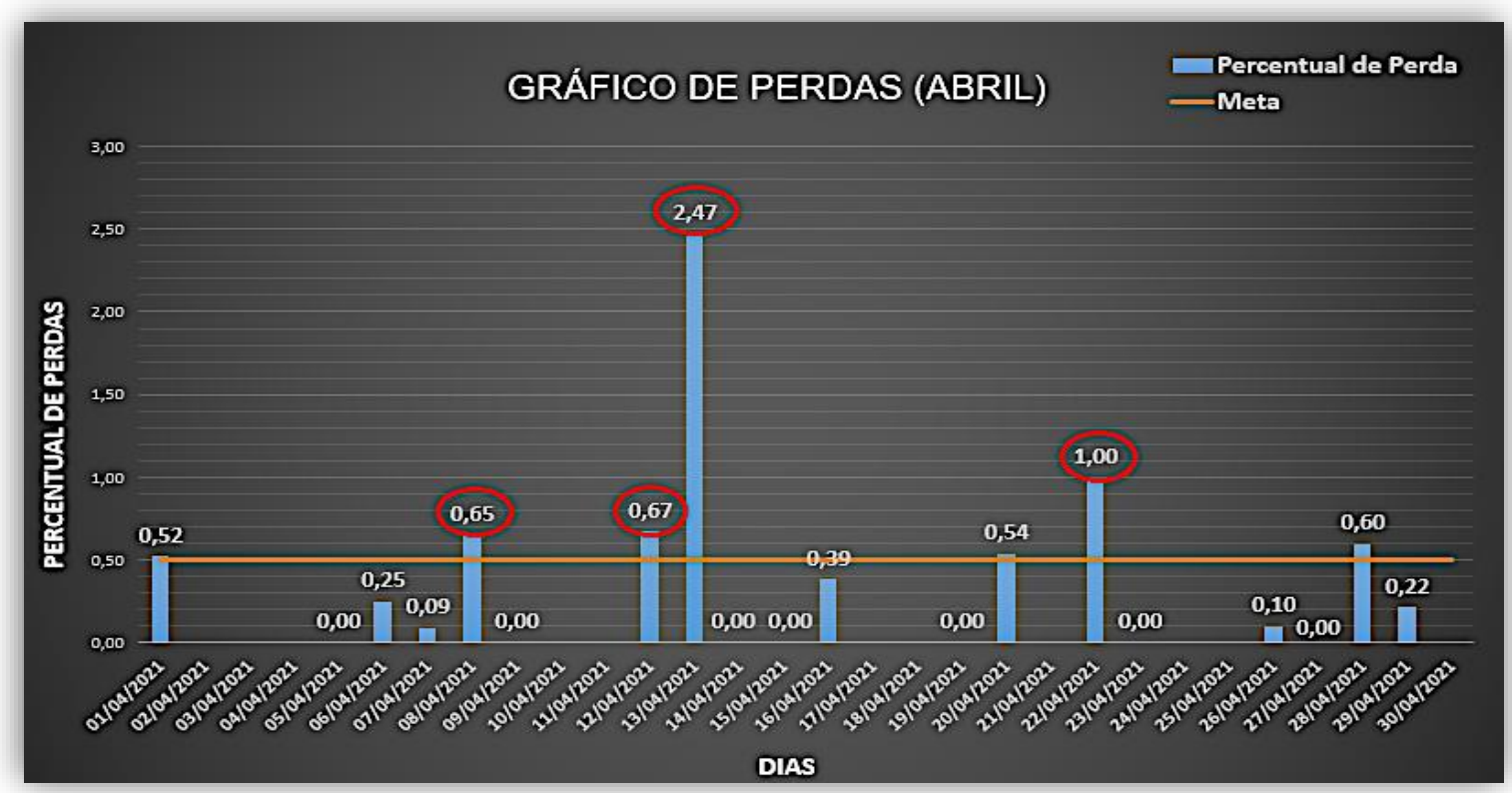

Fonte: Autores (2021).

O último mês analisado foi o mês de maio, que apresentou o melhor resultado da análise, os pontos acima da média sequenciais foram ocasionados devido a matéria-prima, o lote de chapas de vidro incolor de 6 milímetros apresentou um número muito elevado de bolhas internas, material esse de maior volume de pedidos, acarretando em grandes quantidades de quebras no corte, e também no tratamento térmico de têmpera, ao encerrar o lote desse material foi notório a melhoria do setor de corte, alcançando $0,23 \%$ de perda mensal, como mostrado no gráfico a seguir.

Gráfico 6. Análise diária de perdas referente ao mês de maio.

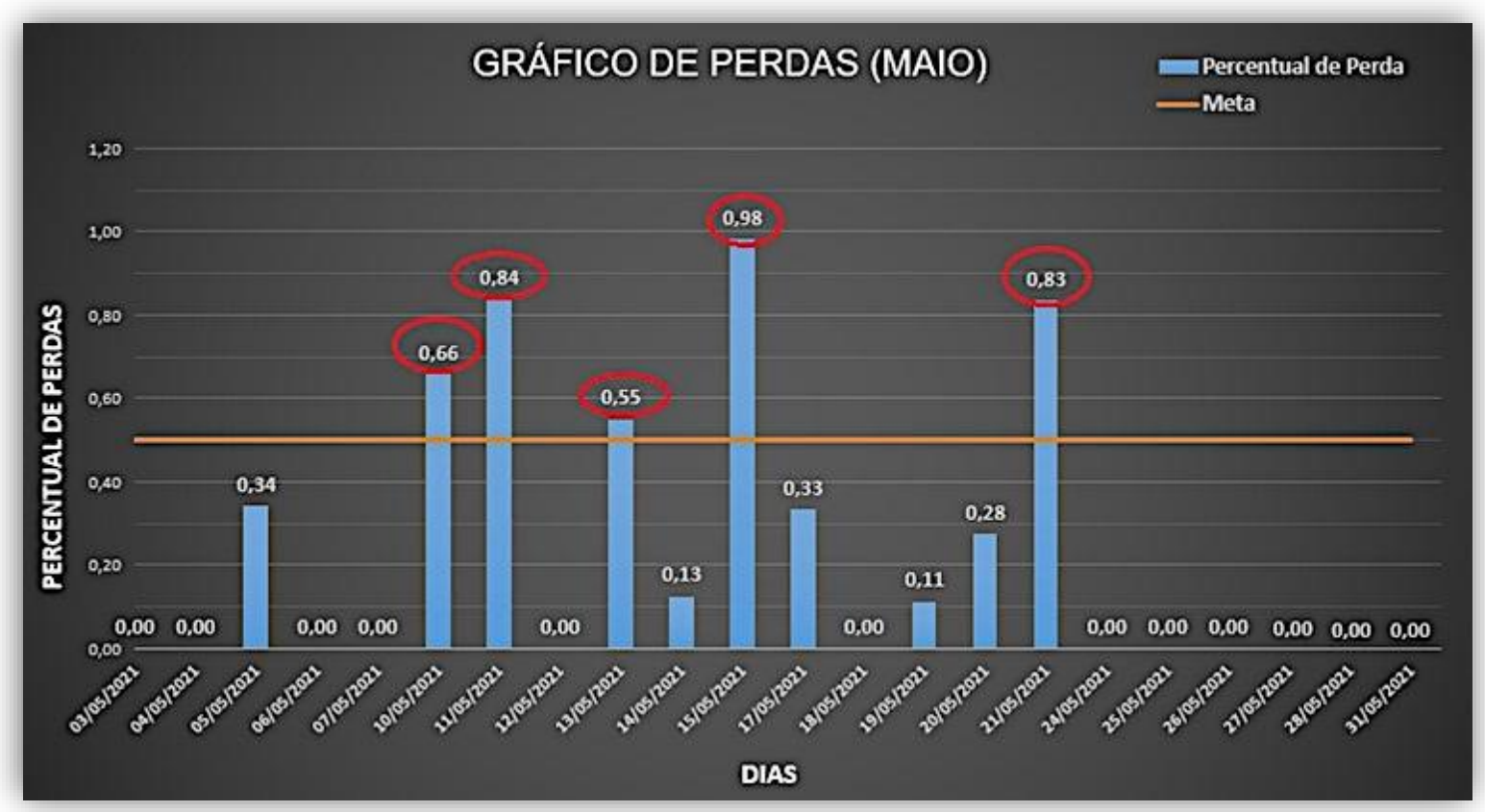

Fonte: Autores (2021). 
Citação (APA): Carvalho, F. L. S., de. \& Mattos, T. de N. (2022). Aplicação de ferramentas de gestão visando a redução de perdas no processo de produção em uma fábrica de vidros capixaba. Brazilian Journal of Production Engineering, 8(2), 99-115.

Ao concluir o estudo de caso, foi possível notar que as modificações realizadas foram bastante eficazes, com o último mês mensurado apresentando um valor 12 vezes menor do que o primeiro mês analisado. De acordo com a tabela a seguir identifica-se os dados obtidos durante a realização da pesquisa.

Tabela 1. Apresentação dos dados da pesquisa.

\begin{tabular}{c|c|c|c|c|c|c|c|}
\hline \multicolumn{7}{|c}{ PERDAS NO SETOR DE CORTE } \\
\hline Data & Qtd. Peças Perdidas & Área das peças $\left(\mathrm{m}^{2}\right)$ & Peças Produzidas $\left(\mathrm{m}^{2}\right)$ & Quantidade de Peças Produzidas & Percentual de Perda & Meta & Valor Rs \\
\hline OUTUBRO & 267 & 228,76 & 8740,12 & 11200 & 2,80 & 0,50 & 36062,31 \\
\hline MOVEMBRO & 198 & 165,41 & 7183,45 & 13269 & 2,30 & 0,50 & 24944,55 \\
\hline DEZEMBRO & 71 & 61,64 & 6443,58 & 7812 & 1,02 & 0,50 & 10237,76 \\
\hline JANEIRO & 32 & 32,59 & 6911,48 & 8754 & 0,52 & 0,50 & 4683,52 \\
\hline FEVEREIRO & 25 & 26,17 & 6838,17 & 7643 & 0,44 & 0,50 & 4788,38 \\
\hline MARÇ0 & 27 & 23,07 & 8417,41 & 10569 & 0,38 & 0,50 & 3758,36 \\
\hline ABRIL & 30 & 24,92 & 7459,72 & 9262 & 0,37 & 0,50 & 4306,60 \\
\hline MAIO & 33 & 26,08 & 11136,92 & 13810 & 0,23 & 0,50 & 3062,21 \\
\hline
\end{tabular}

Fonte: Autores (2021).

A avaliação de eficácia é visualmente muito positiva, apresentando grande queda no número de perdas conforme passaram-se os meses. O Gráfico 7 representa o resultado final da pesquisa, comparando o antes e depois das melhorias.

Gráfico 7. Percentual mensal de perdas no setor do corte durante o período analisado.

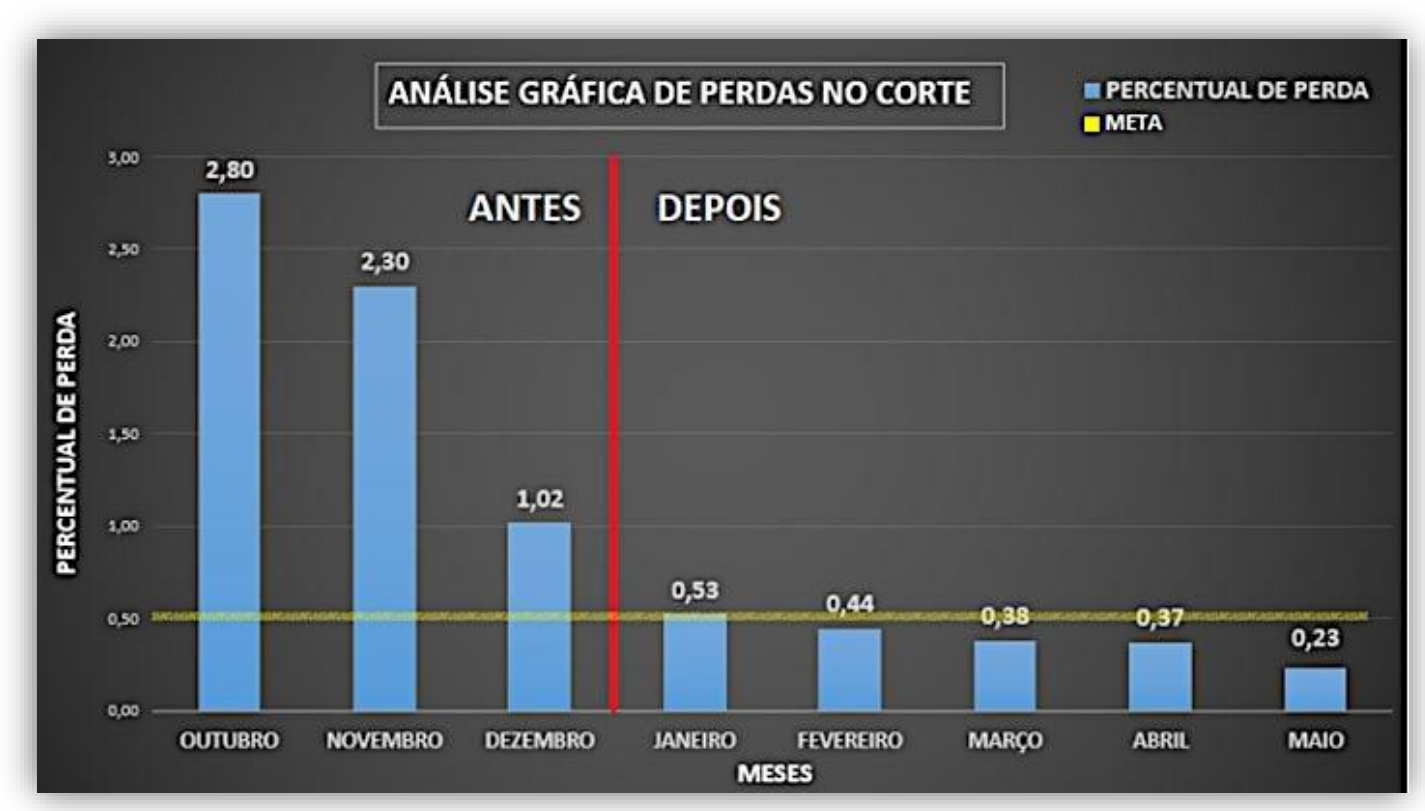

Fonte: Autores (2021).

\subsubsection{Padronização e ações futuras (Act)}

Analisando os resultados obtidos através da aplicação das ferramentas de gestão, foi estipulado que os métodos de corte, destaque e transporte de vidros deveriam ser padronizados, tal como os gastos com melhorias nas condições de trabalho, que foram pagos de acordo com os valores economizados através da redução no número de perdas.

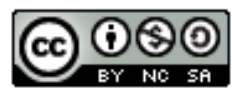



processo de produção em uma fábrica de vidros capixaba. Brazilian Journal of Production Engineering, 8(2), 99-115.

As próximas ações buscando resultados serão feitas após uma nova análise organizacional utilizando a ferramenta diagrama de Pareto, verificando o setor que apresentar maiores números de perdas, visando identificar as causas e reaplicando o ciclo de melhoria contínua. Outro estudo que será desenvolvido futuramente ocorrerá no setor de corte novamente, viabilizando a redução da meta para uma margem de 0,40 a $0,45 \%$ de perdas, buscando novos resultados e garantido a qualidade no processo de produção e entrega dos produtos.

\section{CONCLUSÕES}

O cenário produtivo atual exige das empresas uma vantagem competitiva para sua permanência no mercado, a mais impactante é entrega de um produto ou serviço de baixo preço e alta qualidade, porém para atingir esses valores e obter retorno, é necessária a gestão e controle dos processos de maneira cíclica, implicando na redução das perdas, podendo reduzir o custo final sem aumentar o custo de produção, gerando a capitação de novos clientes.

Nota-se que o objetivo da pesquisa foi atingido, identificando o motivo das perdas e atuando para a redução dos custos de produção, norteando decisões assertivas para empresa através do controle dos processos. As medidas tomadas junto ao gestor foram de suma relevância para atingir a redução no número de perdas, proporcionando oportunidades de melhoria contínua e competitividade no âmbito produtivo.

Futuramente seguindo a otimização dos processos, analisando e quantificando as perdas será possível verificar o atual setor que apresentar maiores perdas e realizar a aplicação de novas ferramentas de gestão, servindo de base para a criação de diferentes procedimentos objetivando a melhoria dos processos. A metodologia utilizada na pesquisa é de fácil entendimento e utilização, podendo ser adaptada e utilizada em diferentes empresas, seja de pequeno, médio ou grande porte gerando resultados. A empresa analisada apresentava falta de acompanhamento no processo de corte, e ao mensurar e quantificar as perdas foi nítido a oportunidade de melhoria que foi desenvolvida no tópico 4.6.1 da pesquisa.

Baseado na análise realizada, foi constatado que os métodos eram os maiores causadores das perdas, e a partir desse ponto foi montado o plano de ação para padronizar os métodos e gerir os riscos ao realizar as atividades, estipulando novas técnicas de trabalho reduzindo os prejuízos no processo, apresentando 4 dos 5 meses analisados com percentual de perdas abaixo da meta, indicando a eficácia dos novos procedimentos e da pesquisa em si. Também foi possível notar que as ações corretivas desenvolvidas a partir da identificação de problemas foram tratadas em períodos muito curtos, gerando uma estatística mais íntegra referente ao procedimento executivo das atividades.

Por fim a pesquisa foi de grande importância não somente para a organização em si, mas também para o âmbito da engenharia de produção, comprovando a eficácia das ferramentas de gestão utilizadas por diversas empresas para a identificação e resolução de problemas. A organização analisada colaborou muito, fornecendo os dados e informações necessárias, tal como acatando as sugestões de melhorias, possibilitando o desenvolvimento do estudo de caso

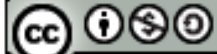



processo de produção em uma fábrica de vidros capixaba. Brazilian Journal of Production Engineering, 8(2), 99-115.

\section{REFERÊNCIAS}

ABIVIDRO. (2004). Anuário 2003. Associação técnica Brasileira das Indústrias Automáticas de Vidro.

Akerman, M (2013). Introdução ao Vidro Plano e sua Produção. Escola de vidro. São Paulo, USP.

Carvalho, M. \& Paladini, E. (2019). Gestão da qualidade: teoria e prática. São Paulo: $4^{\mathrm{a} e d i c ̧ a ̃ o, ~}$ Editora Atlas.

Chiavenato, I. \& Sapiro, A. (2015). Planejamento Estratégico: fundamentos e aplicações.

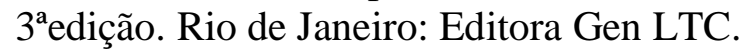

Ewald R. \& Silva, C. (2020). Inovação em sistemas de produção na era da indústria 4.0 Teresina: Kindle Direct Publishing, $1^{\text {a }}$ Edição.

Giacomin, E. \& Freitas, V. P., de. (2012). Material o vidro. Faculdade de Engenharia da Universidade do Porto - Porto Portugal.

Ishikawa, K. (1993). Controle de qualidade total: à maneira japonesa. Rio de Janeiro: Campos. Maia, S. B. (2003). O Vidro e Sua Fabricação - Interciência, Rio de Janeiro.

Oliveira, D. (2013). Sistemas, organização e métodos: uma abordagem gerencial - 21. ed. São Paulo: Editora Atlas.

Paladini, E. (2011). Avaliação estratégica da qualidade. 2aedição, São Paulo: Editora Atlas.

Peinaldo, J. \& Reis, A. (2007). Administração da produção: operações industriais e de serviços - Curitiba: UnicenP.

Santos, W. J. (2000). Caracterização de vidros planos transparentes comerciais. Laboratório de Engenharia de Materiais, Universidade do Extremo Sul Catarinense - UNESC, 88806-000, Criciuma-SC, Brasil.

Seleme, R. \& Stadler, H. (2012). Controle da qualidade: as ferramentas essenciais. $2^{\mathrm{a} e d i c ̧ a ̃ o, ~}$ Curitiba: Ibpex Editora - Intersaberes.

Silva, A. O., Roratto, L., Servat, M. E., Dorneles, L., \& Polacinski, E. (2013). Gestão da qualidade: Aplicação da ferramenta $5 \mathrm{~W} 2 \mathrm{H}$ como plano de ação para projeto de abertura de uma empresa. Horizontina.

Shahir, H. Y., Daneshpajouh, S., \& Ramsin, R. (2008). Improvement strategies or agile processes: a SWOT analysis approach. In: Proc. of the SERA Conference, p. 221-227.

Shewhart, W. A. \& Deming, W. E. (1986). Statistical method from the viewpoint of quality control - Courier Corporation.

Shiba, S., Graham, A., \& Walden, D. (1997). TQM - quatro revoluções na gestão da qualidade. Porto Alegre, Artes Médicas.

Slack, N., Brandon-Jones, A., \& Johnston, R. (2018). Administração da Produção. $8^{\mathrm{a} e d i c ̧ a ̃ o ~}$ São Paulo Editora Atlas.

Tooley, F. V. (1984). The Handbook of Glass Manufature - Ashlee, New York.

Tubino, D. (2017). Planejamento e Controle da Produção: teoria e prática - $3^{\mathrm{a}}$ edição São Paulo. Editora Atlas.

Ujlman, D. R. \& Kreidl, N. J. (1984). Glass Science and Technology. 2, Processing I, Academic Press, Orlando.

Ujlman, D. R. \& Kreidl, N. J. (1986). Glass Science and Technology. 3, Viscosity and Relaxation, Orlando. 